\title{
Article \\ Effort-Reward Imbalance at Work and Drug Misuse: Evidence from a National Survey in the U.S.
}

\author{
Jian Li ${ }^{1,2, * \mathbb{D}}$, Timothy A. Matthews ${ }^{1} \mathbb{D}$, Liwei Chen ${ }^{3}$, Marissa Seamans ${ }^{3}$, Constanze Leineweber ${ }^{4}(\mathbb{D}$ \\ and Johannes Siegrist ${ }^{5}$ (D)
}

1 Department of Environmental Health Sciences, Fielding School of Public Health, University of California, Los Angeles, Los Angeles, CA 90095, USA; tmatthews@ucla.edu

2 School of Nursing, University of California, Los Angeles, Los Angeles, CA 90095, USA

3 Department of Epidemiology, Fielding School of Public Health, University of California, Los Angeles, Los Angeles, CA 90095, USA; cliwei86@ucla.edu (L.C.); mseamans@ph.ucla.edu (M.S.)

4 Department of Psychology, Stockholm University, 11419 Stockholm, Sweden; constanze.leineweber@su.se

5 Institute of Medical Sociology, Faculty of Medicine, University of Düsseldorf, 40225 Düsseldorf, Germany; siegrist@uni-duesseldorf.de

* Correspondence: jianli2019@ucla.edu

check for updates

Citation: Li, J.; Matthews, T.A.; Chen, L.; Seamans, M.; Leineweber, C.; Siegrist, J. Effort-Reward Imbalance at Work and Drug Misuse: Evidence from a National Survey in the U.S. Int J. Environ. Res. Public Health 2021, 18, 13334. https://doi.org/10.3390/ ijerph182413334

Academic Editors: Els Clays and Pau B. Tchounwou

Received: 6 November 2021

Accepted: 15 December 2021

Published: 17 December 2021

Publisher's Note: MDPI stays neutra with regard to jurisdictional claims in published maps and institutional affiliations.

Copyright: (C) 2021 by the authors Licensee MDPI, Basel, Switzerland This article is an open access article distributed under the terms and conditions of the Creative Commons Attribution (CC BY) license (https:// creativecommons.org/licenses/by/ $4.0 /)$.

\begin{abstract}
With the rise of drug misuse among workers in recent years, preliminary research on potential risk factors in the workplace of single-type of drug misuse has been reported. This is the first study to examine cross-sectional associations of work stress, in terms of effort-reward imbalance, with multiple drug misuse (including any drug misuse, opioid misuse, sedatives misuse, cannabis misuse, and other drug misuse) during the past 12 months in a national sample of U.S. workers. Data of 2211 workers were derived from the nationally representative and population-based Midlife in the United States (MIDUS) study. Internal consistency reliability and factorial validity of a 17-item effort-reward imbalance measure were robust and satisfactory. After adjustment for relevant covariates, logistic regression analyses showed that workers experiencing effort-reward imbalance at work had significantly higher odds of any drug misuse (OR and 95\% CI $=1.18(1.03,1.37)$ ), especially opioid misuse (OR and 95\% CI = $1.35(1.07,1.69)$ ) and other drug misuse (OR and 95\% CI = 1.36 $(1.01,1.83))$. The findings suggest that a stressful work environment may act as a determinant of drug misuse, and further prospective evidence is needed.
\end{abstract}

Keywords: effort-reward imbalance; work stress; drug misuse; opioid; cannabis; workers

\section{Introduction}

Among the many risk factors of drug misuse and overdose, work-related conditions have received special attention in recent research. This holds particularly true for opioids [1-5], cannabis [6-8], and benzodiazepines [9,10]. Increased emphasis on this topic resulted from practical concerns, most obviously from the documented excess mortality of opioid overdose among working people $[1,3,11]$. Several of these studies explored distinct stressful aspects within the complexities of modern work environments and the results suggest that psychosocial hazards are more prevalent than physical hazards [12]. To this end, theoretical models are needed. These models are delineated at a level of generalization that allows for their identification in a wide range of different occupations and contexts. To this end, they focus on core aspects of working people's crucial needs that are threatened by an adverse work environment, such as the need for security [13], the need for control and autonomy [14], or the need for reward and recognition [15]. Rooted in biopsychosocial stress theory [16,17], these models offer explanations of observed associations of adverse work environments with elevated health risks, including substance use and addiction. In this context, two models received special attention in international investigations: the demand-control model [14,18], and the effort-reward imbalance (ERI) 
model $[15,19]$. The former model, often labelled job strain, posits that job task profiles defined by a combination of high psychological demands and low control, or low degree of decision latitude, elicit sustained arousal with negative effects on a variety of health outcomes. The latter approach claims that lack of reciprocity between efforts spent at work and rewards received in turn is associated with strong negative emotions and sustained biological stress responses. In this model, rewards include salary or wage, job security, promotion prospects and esteem.

As it is difficult to clearly distinguish between medically prescribed drugs and drug misuse, several investigations testing these models focused on the former criterion. On balance, for both criteria, there is some evidence that these concepts of a stressful psychosocial work environment are related to an increased use of opioids [4,20], benzodiazepines [9], cannabis [21], and other psychotropic substances [10,22-25]. As a general limitation of current research on this topic, many studies examined just one type of drug misuse as the outcome. However, given the fact that drug misuse is often extended to a variety of substances [26,27], there is a need to investigate associations of stressful work with a comprehensive set of indicators of drug misuse. While two large-scale studies explored this relationship with indicators of the job strain model [28,29], a respective test based on the effort-reward imbalance, to our knowledge, has not yet been conducted. To fill this knowledge gap, we aimed to examine the hypothesis that effort-reward imbalance at work is associated with an elevated odds of reporting misuse of opioids, sedatives, cannabis, and other drugs, using data from a national survey among employed people in the United States (U.S.).

\section{Materials and Methods}

\subsection{Study Population}

Data from the second wave of the Midlife in the United States (MIDUS) [30] were used for this cross-sectional investigation. The MIDUS study is an ongoing nationally representative, population-based, longitudinal study examining psychological, social, and behavioral factors and health among U.S. adults aged 25-74 years. The second wave of the MIDUS survey was carried out from 2004 to 2006. Data collection was primarily based on random digit dial (RDD) phone interviews and an extensive self-administered questionnaire (SAQ). In total, 4963 people participated in the second wave of the MIDUS study, and 2313 reported that they were working. Among them, 2211 workers (95.6\%) had complete data on ERI and drug misuse used for the current analyses.

\subsection{Measures}

The original ERI questionnaire [31] was not applied into the MIDUS study. Using existing items of psychosocial work characteristics, a proxy measure of ERI at work was constructed accordingly. It contains two 4-point Likert scales, "Effort" and "Reward": ten items for "Effort", including two subscales "Mental effort" (5 items) and "Physical effort" (5 items), and seven items for "Reward", including three subscales "Job promotion" (4 items), "Esteem" ( 2 items) and "Job security" (1 item), corresponding to the structure of the original ERI questionnaire [31] (for details, please see the Table A1). For each scale or subscale, scores are determined by summing up point values for its items. Higher scores indicate higher effort and higher reward, respectively. Moreover, according to a predefined algorithm, a ratio between the two scales "Effort" and "Reward" was calculated to quantify the degree of mismatch between high 'cost' and low 'gain' at the individual level (weighed by numbers of items) [31].

The outcome of interest was drug misuse, which was defined according to the World Health Organization Composite International Diagnostic Interview short-form (CIDI-SF) [32], in accordance with the American Psychiatric Association Diagnostic and Statistical Manual of Mental Disorders, Revised Third Edition (DSM-III-R) [33]. The study participants were asked about their experiences during the past 12 months regarding ten types of drugs or substances (i.e., sedatives, tranquilizers, amphetamines, analgesics/prescription 
painkillers, anti-depressants, inhalants, marijuana/hashish, cocaine/crack/free base, hallucinogens, and heroin) "on your own", which referred to "without a doctor's prescription, in larger amounts than prescribed, or for a longer period than prescribed". Under analgesics/prescription painkillers, a note stated "This does not include normal use of aspirin, Tylenol without codeine, etc., but does include use of Tylenol with codeine and other prescribed painkillers like Demerol, Darvon, and Percodan". We followed prior established operationalizations of drug misuse in the MIDUS study [34]: analgesics/prescription painkillers and heroin were categorized as "opioid misuse", sedatives and tranquilizers were combined into the category of "sedatives misuse", marijuana/hashish as "cannabis misuse", and the remaining drug types were grouped as "other drug misuse"; in cases where an individual reported any type of ten drugs, they were labelled as "any drug misuse".

Several sociodemographic factors and health-related behaviors were included, including age ( $\leq 45 ; 46$ to 55 ; and $\geq 56$ years old), sex, marital status (married; never married; and others), race (white; black, and others), education (high school or less; some college; university or more), annual household gross income $(<\$ 60,000 ; \$ 60,000$ to $\$ 99,999 ; \geq \$ 100,000)$, current smoking (no; and yes), alcohol consumption (low or moderate drinking-up to two drinks per day for men and one drink per day for women; heavy drinking-more than moderate drinking, [35]), and leisure-time physical activity (low; moderate; and high). Moreover, two potential mediators, pain and depressive affect, were also measured, given their significant impact on drug misuse [34]. Pain was considered as lower backaches and aches/stiffness in joints, depressive affect was determined by the CIDI-SF [34].

\subsection{Statistical Analysis}

Following descriptive analyses, we first used established procedures to test the psychometric properties of the proxy ERI measure. Cronbach's alpha coefficients were calculated to assess internal consistency (values over 0.70 indicating satisfactory reliability). Factorial validity was tested with confirmatory factor analysis, which provided the closest representation of the theoretical structure, with two second-order factors "Effort" and "Reward" loading on a third-order factor representing the latent ERI construct, and with the components "Mental effort" and "Physical effort" identified as first-order factors loading on the "Effort" factor, as well as components "Job promotion", "Esteem" and "Job security" identified as first-order factors loading on the "Reward" factor. We used the goodness-of-fit index (GFI), which indicates the amount of variance and covariance explained by the model (values over 0.90 indicating acceptable fit). Next, means and standard deviations (SDs) of ERI scales and subscales were computed, where we compared the differences between groups of drug misuse "No" and "Yes" using student's $t$ test. Finally, associations between all single scales and subscales of the ERI measure (increase or decrease per SD continuously) and drug misuse were estimated using logistic regression, and were expressed as odds ratios (ORs), with 95\% confidence intervals (CIs). Multivariable models were calculated in three steps: Model I was adjusted for age, sex, marital status, race, education, and household income; further adjustment for smoking, alcohol drinking, and physical activity was added in Model II; Model III additionally adjusted for pain and depressive affect. We verified the fit of the logistic regression models with the Hosmer-Lemeshow goodness of fit test. In all cases, the models fit well $(p>0.05)$. All statistical analyses were performed with the program SAS 9.4 (SAS Inst., Inc., Cary, NC, USA).

\section{Results}

Table 1 shows the characteristics of the study sample. The 2211 participants in the sample were predominantly middle-aged, with a roughly equal proportion of men and women. Most participants were white and were married. The majority of participants had at least some college education. Most participants were non-smokers, had low or moderate alcohol drinking, and engaged in moderate-to high leisure-time physical activity. Approximately $30 \%$ and $7 \%$ of individuals reported pain and depressive affect, respectively. 
Table 1. Characteristics of the study sample $(N=2211)$.

\begin{tabular}{ccc}
\hline Variables & & $\boldsymbol{N}(\mathbf{\%})$ \\
\hline Age (years) & $\leq 45$ & $702(31.75)$ \\
& $46-55$ & $827(37.40)$ \\
Gender & $\geq 56$ & $682(30.85)$ \\
& Men & $1083(48.98)$ \\
Marital status & Women & $1128(51.02)$ \\
& Married & $1626(73.55)$ \\
Race & Never married & $194(8.77)$ \\
& Others & $391(17.68)$ \\
Education: & White & $2036(92.09)$ \\
& Black & $72(3.25)$ \\
Annual household income (US $\$)$ & Others & $103(4.66)$ \\
& High school or less & $590(26.68)$ \\
& Some college & $629(28.45)$ \\
Current smoking & University or more & $992(44.87)$ \\
& $<60,000$ & $820(37.09)$ \\
Alcohol drinking & $60,000-99,999$ & $719(32.52)$ \\
& $\geq 100,000$ & $672(30.39)$ \\
Leisure-time physical activity & No & $1882(85.12)$ \\
& Yes & $329(14.88)$ \\
Pepressive affect & Low or moderate & $2159(97.65)$ \\
& Heavy & $52(2.35)$ \\
& Low & $520(23.52)$ \\
& Moderate & $795(35.96)$ \\
& High & $896(40.52)$ \\
& No & $1562(70.65)$ \\
& Yes & $649(29.35)$ \\
& No & $2047(92.58)$ \\
& Yes & $164(7.42)$ \\
\hline
\end{tabular}

The Cronbach's alpha coefficients for the two scales of effort and reward were 0.74 and 0.76 , respectively; for subscales of mental effort, physical effort, job promotion, and esteem, they were $0.76,0.82,0.72$, and 0.83 , respectively. Regarding factorial validity of the theoretical structure of the ERI measure, the third-order model represents a satisfactory fit to the data (e.g., GFI > 0.90) (see Figure 1).

The overall prevalence of any drug misuse was $11.5 \%$ in the MIDUS study subjects. Specifically, 3.9\% with opioid misuse, $4.0 \%$ with sedatives misuse, $4.7 \%$ with cannabis misuse, and $2.4 \%$ with other drug misuse. The differences of ERI scales and subscales scores by drug misuse are given in Table 2. In general, individuals who reported drug misuse had significantly higher effort (especially physical effort), lower reward (especially job promotion), and a higher E-R ratio. Regarding the results of logistic regression analyses, as evident from Table 3, the series of adjusted models demonstrated several significant associations of effort-reward imbalance at work with drug misuse. In the fully adjusted model, taking the potentially mediating variables of pain and depressive affect into account, the theoretically important E-R ratio was associated with significantly elevated ORs of 1.18 $(1.03 ; 1.37)$ for any drug misuse, $1.35(1.07 ; 1.69)$ for opioid misuse, and $1.36(1.01 ; 1.83)$ for other drug misuses. Among single scales, effort (in particular physical effort) was associated with any drug misuse and with cannabis misuse, while reward, specifically job promotion, was associated with opioid misuse and with other drug misuses. No associations were observed for sedatives misuse, and only weak relations with cannabis misuse. 


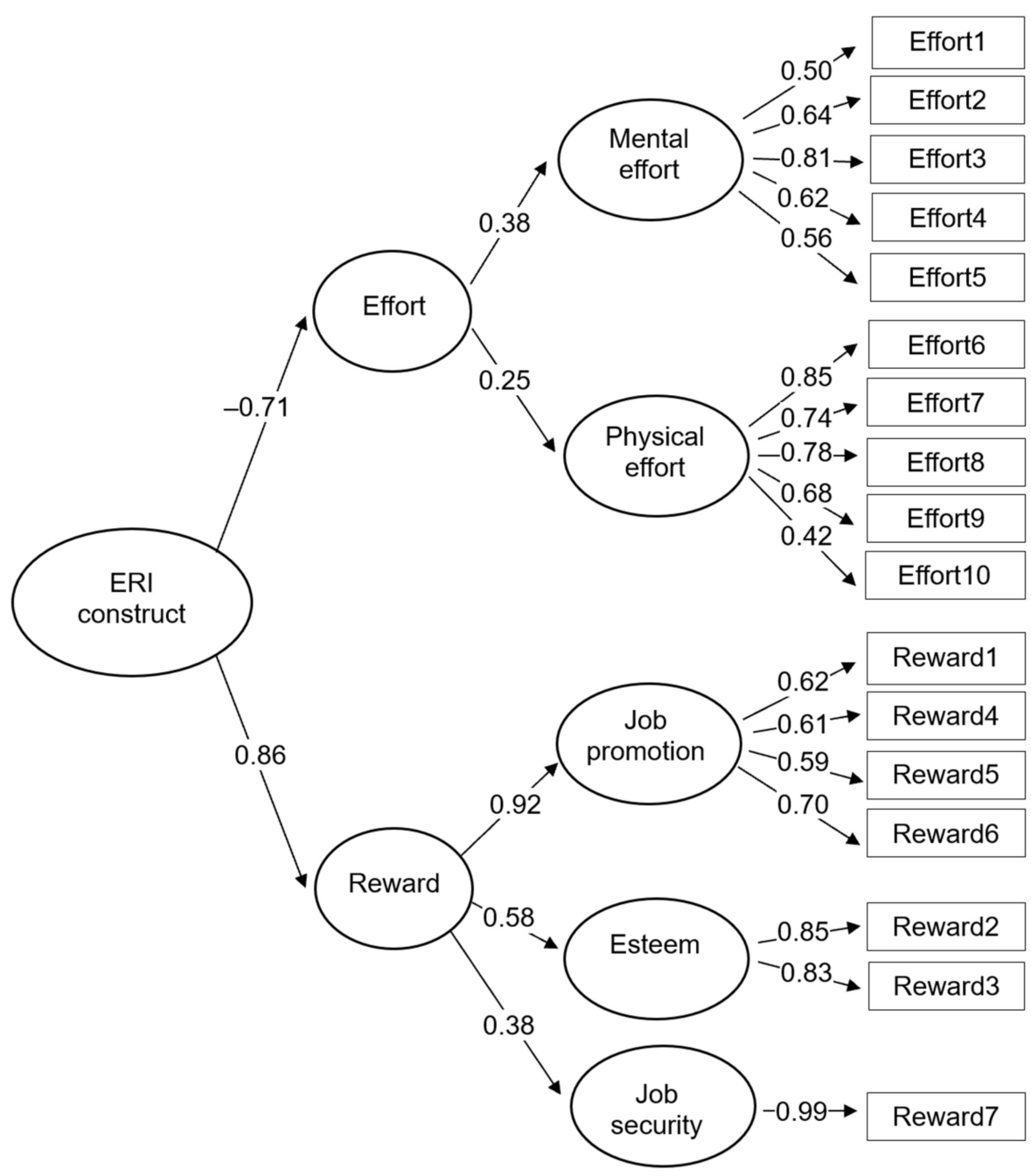

Figure 1. Confirmatory factor analysis testing the theoretical construct underlying the ERI measure.

Table 2. Scores of effort-reward imbalance at work by drug misuse [means (SDs)].

\begin{tabular}{lccc}
\hline & Drug Misuse: No & Drug Misuse: Yes & $p$ \\
\hline \multicolumn{1}{c}{ Any drug misuse } & $N=1956(88.47 \%)$ & $N=255(11.53 \%)$ & \\
Effort & $24.36(5.19)$ & $25.49(5.04)$ & 0.0011 \\
Mental effort & $12.90(2.98)$ & $12.90(2.96)$ & 0.9632 \\
Physical effort & $11.46(3.97)$ & $12.58(4.08)$ & $<0.0001$ \\
Reward & $24.29(3.42)$ & $23.78(3.58)$ & 0.0269 \\
Job promotion & $13.65(2.29)$ & $13.32(2.34)$ & 0.0317 \\
Esteem & $7.11(1.30)$ & $6.94(1.35)$ & 0.0622 \\
Job security & $3.53(0.83)$ & $3.52(0.81)$ & 0.7633 \\
E-R ratio & $0.72(0.22)$ & $0.77(0.24)$ & 0.0002 \\
$\quad$ Opioid misuse & $2125(96.11 \%)$ & $N=86(3.89 \%)$ & \\
Effort & $24.42(5.18)$ & $26.08(5.24)$ & 0.0037 \\
Mental effort & $12.88(2.98)$ & $13.34(3.00)$ & 0.1633 \\
Physical effort & $11.54(3.97)$ & $12.74(4.40)$ & 0.0063 \\
Reward & $24.28(3.42)$ & $23.14(3.88)$ & 0.0027 \\
Job promotion & $13.64(2.28)$ & $12.84(2.59)$ & 0.0016 \\
Esteem & $7.10(1.31)$ & $6.82(1.41)$ & 0.0572 \\
Job security & $3.54(0.83)$ & $3.46(0.84)$ & 0.4425 \\
E-R ratio & $0.72(0.22)$ & $0.83(0.32)$ & 0.0017 \\
\hline
\end{tabular}


Table 2. Cont.

\begin{tabular}{lccc}
\hline & Drug Misuse: No & Drug Misuse: Yes & $p$ \\
\hline Sedatives misuse & $N=2122(95.97 \%)$ & $N=89(4.03 \%)$ & \\
Effort & $24.49(5.20)$ & $24.36(4.82)$ & 0.8096 \\
Mental effort & $12.92(2.97)$ & $12.42(3.25)$ & 0.1195 \\
Physical effort & $11.58(4.010$ & $11.94(3.60)$ & 0.3960 \\
Reward & $24.24(3.45)$ & $24.09(3.40)$ & 0.6884 \\
Job promotion & $13.61(2.30)$ & $13.55(2.16)$ & 0.7968 \\
Esteem & $7.09(1.31)$ & $6.96(1.33)$ & 0.3249 \\
Job security & $3.53(0.83)$ & $3.58(0.76)$ & 0.5459 \\
E-R ratio & $0.73(0.22)$ & $0.73(0.21)$ & 0.9916 \\
Cannabis misuse & $N=2108(95.34 \%)$ & $N=103(4.66 \%)$ & 0.0079 \\
Effort & $24.42(5.20)$ & $25.82(4.65)$ & 0.3610 \\
Mental effort & $12.91(3.00)$ & $12.67(2.56)$ & $<0.0001$ \\
Physical effort & $11.52(3.98)$ & $13.14(4.06)$ & 0.7913 \\
Reward & $24.24(3.45)$ & $24.14(3.27)$ & 0.4280 \\
Job promotion & $13.62(2.30)$ & $13.44(2.19)$ & 0.5995 \\
Esteem & $7.08(1.31)$ & $7.16(1.29)$ & 0.7915 \\
Job security & $3.53(0.83)$ & $3.55(0.76)$ & 0.0895 \\
E-R ratio & $0.73(0.23)$ & $0.77(0.19)$ & \\
Other drug misuse & $N=2159(97.65 \%)$ & $N=52(2.35 \%)$ & 0.0773 \\
Effort & $24.45(5.15)$ & $26.06(6.38)$ & 0.6956 \\
Mental effort & $12.89(2.98)$ & $13.06(3.16)$ & 0.0101 \\
Physical effort & $11.56(3.98)$ & $13.00(4.41)$ & 0.0003 \\
Reward & $24.27(3.43)$ & $22.54(3.64)$ & 0.0006 \\
Job promotion & $13.64(2.28)$ & $12.54(2.42)$ & 0.0135 \\
Esteem & $7.10(1.30)$ & $6.54(1.58)$ & 0.5327 \\
Job security & $3.53(0.83)$ & $3.46(0.78)$ & \\
E-R ratio & $0.73(0.22)$ & $0.85(0.31)$ & \\
\hline Differences were & & & \\
\hline
\end{tabular}

Differences were determined by student's $t$ test; SD: standard deviation.

Table 3. Associations of effort-reward imbalance at work with drug misuse (odds ratios (ORs) and 95\% confidence intervals (CIs)).

\begin{tabular}{lrrrr}
\hline & & Model I & Model II & Model III \\
\hline & Any drug misuse & & & \\
Effort & (increase per SD) & $\mathbf{1 . 2 0}(1.05,1.38)$ & $\mathbf{1 . 1 9}(1.04,1.37)$ & $\mathbf{1 . 1 6}(1.01,1.34)$ \\
Mental effort & (increase per SD) & $0.98(0.85,1.12)$ & $0.97(0.85,1.11)$ & $0.93(0.81,1.07)$ \\
Physical effort & (increase per SD) & $\mathbf{1 . 3 2}(1.14,1.52)$ & $\mathbf{1 . 3 0}(1.13,1.50)$ & $\mathbf{1 . 2 9}(1.12,1.49)$ \\
Reward & (decrease per SD) & $1.11(0.98,1.27)$ & $1.11(0.97,1.27)$ & $1.08(0.95,1.24)$ \\
Job promotion & (decrease per SD) & $1.10(0.97,1.25)$ & $1.10(0.96,1.26)$ & $1.07(0.94,1.23)$ \\
Esteem & (decrease per SD) & $1.11(0.98,1.26)$ & $1.10(0.97,1.25)$ & $1.08(0.95,1.23)$ \\
Job security & (decrease per SD) & $1.01(0.88,1.15)$ & $1.01(0.88,1.15)$ & $1.00(0.88,1.14)$ \\
E-R ratio & (increase per SD) & $\mathbf{1 . 2 4}(1.08,1.42)$ & $\mathbf{1 . 2 3}(1.06,1.41)$ & $\mathbf{1 . 1 8}(1.03,1.37)$ \\
& (increase per SD) & $\mathbf{1 . 3 0}(1.04,1.63)$ & $\mathbf{1 . 3 0}(1.03,1.62)$ & $1.24(0.99,1.56)$ \\
Effort & Opioid misuse & $1.16(0.92,1.44)$ & $1.10(0.88,1.38)$ \\
Mental effort & (increase per SD) & $1.17(0.93,1.46)$ & $\mathbf{1 . 2 8}(1.01,1.61)$ & $1.24(0.99,1.57)$ \\
Physical effort & (increase per SD) & $\mathbf{1 . 2 8}(1.01,1.62)$ & $\mathbf{1 . 2 9}(1.05,1.57)$ & $\mathbf{1 . 2 3}(1.00,1.51)$ \\
Reward & (decrease per SD) & $\mathbf{1 . 2 9}(1.06,1.57)$ & $\mathbf{1 . 2 8}(1.05,1.57)$ & $1.23(0.99,1.50)$ \\
Job promotion & (decrease per SD) & $\mathbf{1 . 2 9}(1.06,1.57)$ & $1.20(0.98,1.46)$ & $1.16(0.96,1.42)$ \\
Esteem & (decrease per SD) & $1.20(0.98,1.45)$ & $1.06(0.86,1.30)$ & $1.05(0.86,1.30)$ \\
Job security & (decrease per SD) & $1.06(0.86,1.30)$ & $\mathbf{1 . 4 3}(1.14,1.78)$ & $\mathbf{1 . 3 5}(1.07,1.69)$ \\
E-R ratio & (increase per SD) & $\mathbf{1 . 4 3}(1.15,1.78)$ & &
\end{tabular}


Table 3. Cont.

\begin{tabular}{|c|c|c|c|c|}
\hline & & Model I & Model II & Model III \\
\hline \multicolumn{5}{|c|}{ Sedatives misuse } \\
\hline Effort & (increase per SD) & $1.02(0.82,1.27)$ & $1.02(0.82,1.28)$ & $1.00(0.79,1.25)$ \\
\hline Mental effort & (increase per SD) & $0.89(0.71,1.10)$ & $0.89(0.71,1.10)$ & $0.84(0.67,1.06)$ \\
\hline Physical effort & (increase per SD) & $1.14(0.90,1.43)$ & $1.14(0.90,1.43)$ & $1.13(0.90,1.43)$ \\
\hline Reward & (decrease per SD) & $1.04(0.83,1.29)$ & $1.03(0.83,1.28)$ & $1.00(0.80,1.25)$ \\
\hline Job promotion & (decrease per SD) & $1.01(0.81,1.26)$ & $1.01(0.81,1.26)$ & $0.99(0.79,1.24)$ \\
\hline Esteem & (decrease per SD) & $1.13(0.93,1.38)$ & $1.12(0.91,1.36)$ & $1.09(0.89,1.34)$ \\
\hline Job security & (decrease per SD) & $0.90(0.72,1.13)$ & $0.90(0.71,1.13)$ & $0.89(0.70,1.12)$ \\
\hline E-R ratio & (increase per SD) & $1.05(0.84,1.32)$ & $1.05(0.84,1.32)$ & $1.01(0.80,1.27)$ \\
\hline \multicolumn{5}{|c|}{ Cannabis misuse } \\
\hline Effort & (increase per SD) & $1.14(0.92,1.41)$ & $1.09(0.87,1.36)$ & $1.09(0.87,1.36)$ \\
\hline Mental effort & (increase per SD) & $0.83(0.68,1.03)$ & $0.82(0.66,1.02)$ & $0.81(0.65,1.01)$ \\
\hline Physical effort & (increase per SD) & $1.38(1.11,1.72)$ & $1.32(1.05,1.66)$ & $1.32(1.05,1.66)$ \\
\hline Reward & (decrease per SD) & $0.94(0.76,1.16)$ & $0.95(0.77,1.19)$ & $0.95(0.76,1.19)$ \\
\hline Job promotion & (decrease per SD) & $0.98(0.80,1.21)$ & $1.00(0.81,1.24)$ & $1.00(0.81,1.24)$ \\
\hline Esteem & (decrease per SD) & $0.89(0.71,1.11)$ & $0.89(0.71,1.11)$ & $0.89(0.71,1.11)$ \\
\hline Job security & (decrease per SD) & $0.97(0.78,1.19)$ & $0.99(0.80,1.22)$ & $0.99(0.80,1.22)$ \\
\hline E-R ratio & (increase per SD) & $1.08(0.87,1.34)$ & $1.05(0.84,1.32)$ & $1.06(0.84,1.33)$ \\
\hline \multicolumn{5}{|c|}{ Other drug misuse } \\
\hline Effort & (increase per SD) & $1.27(0.96,1.69)$ & $1.24(0.93,1.65)$ & $1.19(0.89,1.59)$ \\
\hline Mental effort & (increase per SD) & $1.05(0.79,1.40)$ & $1.03(0.78,1.38)$ & $0.95(0.71,1.28)$ \\
\hline Physical effort & (increase per SD) & $1.34(0.99,1.80)$ & $1.30(0.97,1.76)$ & $1.30(0.97,1.75)$ \\
\hline Reward & (decrease per SD) & $1.42(1.11,1.82)$ & $1.42(1.11,1.82)$ & $1.38(1.08,1.78)$ \\
\hline Job promotion & (decrease per SD) & $1.37(1.07,1.75)$ & $1.36(1.06,1.75)$ & $1.34(1.04,1.74)$ \\
\hline Esteem & (decrease per SD) & $1.37(1.09,1.72)$ & $1.36(1.09,1.71)$ & $1.35(1.07,1.69)$ \\
\hline Job security & (decrease per SD) & $1.04(0.80,1.36)$ & $1.05(0.80,1.37)$ & $1.04(0.79,1.35)$ \\
\hline E-R ratio & (increase per SD) & $1.44(1.09,1.92)$ & $1.43(1.07,1.91)$ & $1.36(1.01,1.83)$ \\
\hline
\end{tabular}

Logistic regression. Model I: Adjusted for age, gender, marital status, race, education, and income; Model II: Model I + additionally adjusted for smoking, alcohol drinking, and physical activity; Model III: Model II + additionally adjusted for pain and depressive affect.

\section{Discussion}

In this study, we observed that employed persons experiencing high effort and low reward at work had significantly higher odds ratios of opioid misuse, any drug misuse and other drug misuse (amphetamines, or anti-depressants, inhalants, or cocaine/crack/free base, or hallucinogens). No association was found for sedatives misuse, and cannabis misuse was uniquely related to the component of high physical effort. In subsequent models, effects were adjusted for a comprehensive set of confounding factors and remained robust. Given a cross-sectional study design, we cannot interpret the direction of associations between work stress and drug misuse. For instance, it is possible that drug use earlier on resulted in poor working and employment conditions, thus increasing the probability of experiencing stressful work in terms of this model [29]. In addition, we were not able to rule out that genetic or personality traits and maladaptive coping patterns predispose people to become susceptible to drug consumption, as well as the experience of sustained stress at work [36].

However, previous studies documenting prospective associations of effort-reward imbalance at work with long-term use of benzodiazepine [9] and of alcohol dependence [37] support the notion that stressful work may act as a determinant of drug misuse in this sample. Furthermore, this assumption is in line with the specific stress-theoretical link of this model to the pathways acting through limbic structures of the brain. These structures are sensitive to the experience and omission of reward [38]. As failed reward from social exchange violates basic expectations, thus threatening feelings of self-esteem and reinforcing a sense of being socially excluded, these structures may be activated in excessive ways [39]. Drug misuse offers a way of evoking positive emotional states of reward that buffer these threats [40]. The findings of this study corroborate earlier observations of associations of stressful psychosocial work environments with drug misuse, in particular those based 
on the job strain model mentioned above. Moreover, job insecurity and job loss were found to be related to excessive drug misuse, often resulting in premature mortality $[1,3]$. Nevertheless, prospective cohort studies are needed to validate this preliminary evidence.

It is of interest to note that effort-reward at work was not measured by the original questionnaire [31]. Yet, with a set of proxy indicators available from the MIDUS study, an appropriate assessment was achieved. Effort was assessed by 10 items, allowing the differentiation of mental and physical effort, and reward was measured by 7 items, covering the components of esteem, job promotion, and job security. Cronbach alpha values of scales and subscales, varying from 0.72 to 0.83 , were acceptable, and confirmatory factor analysis replicated the theoretical structure of the model with good indices of fit. These psychometric properties of ERI measure in this U.S. sample are comparable to other validation studies [41], with extensively supportive evidence from European [31], Asian [42,43], and Latin-American countries [44]. Moreover, the ERI model has been used in a couple of studies in the U.S. to examine associations with different health outcomes; however, none of these studies covered general working people in this country, but instead investigated specific occupational strata, such as healthcare workers [45], firefighters [46], taxi drivers [47], cleaners [48], or older workers [49]. Taken together, the 17 items are considered a valid proxy measure of the two extrinsic scales of the effort-reward imbalance model in the U.S. working population, thus justifying the test of hypothesized associations. One critical remark relates to a higher number of items measuring physical effort, compared to the original measure. As two significant associations of this subcomponent with drug misuse were observed, one may ask whether this fact reduces the comparison with similar findings supporting the model's hypotheses. It should be mentioned that a majority of significant associations in this analysis concerned the reward scale (five associations), in addition to the three theoretically prominent associations of the E-R ratio (see Table 3).

This study suffers from several limitations. In addition to its cross-sectional design, information on work stress, as measured by ERI, and drug misuse was collected by selfreport, thus being potentially vulnerable to reporting bias. However, prospective cohort studies demonstrated successful predictions of health outcomes by ERI measures, thus supporting the validity of the measure [19]. Moreover, for large-scale epidemiological surveys, self-reported drug misuse under the framework of CIDI-SF and DSM-III-R is well established and validated $[32,33]$. The time window was restricted to the past 12 months, thus neglecting information on history of drug misuse over the previous life course [34]. The associations might be underestimated due to healthy worker survivor effect - the study participants must be healthy enough (not have debilitating addiction) in order to be employed. Furthermore, no data on personal vulnerability factors, social network constraints or devastating socio-environmental conditions stimulating drug misuse were included. Therefore, the available set of control variables included in logistic regression analyses cannot rule out the risk of confounding by unmeasured factors. Further adjustment for pain and depressive affect resulted in slight attenuation of associations between effort-reward imbalance and drug misuse, suggesting a potential mediating role of pain and depressive affect. Notably, much research evidence has accumulated in terms of effects of effort-reward imbalance at work on pain and depressive disorders [50,51], as well as effects of pain and depressive disorders on drug misuse $[34,52,53]$. We need to point out that the data source of our study came from the second wave of the MIDUS survey (2004-2006, with sample size 2211). Though data of the latest third wave (2013-2014) are available, the sample size of working people was reduced to approximately 1200 . Considering the stability of the ERI structure in previous longitudinal studies [54], we preferred a larger sample to examine ERI psychometric properties. Finally, despite a fair representation of the original ERI measurement, this data set did not include the model's intrinsic component 'over-commitment' and thus may slightly underestimate its explanatory contribution. Conversely, this study also exhibits some major strengths, as it adds to the small number of investigations that explore associations of stressful work with a comprehensive set of indicators of drug misuse, rather than focusing on a single outcome. Moreover, to our knowledge, this is 
the first study documenting consistent associations of a summary measure of the notion of effort-reward imbalance at work, the effort-reward ratio, with elevated probability of any drug misuse, of opioid misuse, and of other drug misuse. These elevated odds ratios remain statistically significant in the fully adjusted models. In addition, the MIDUS study offers a large, nationally representative, population-based sample comprised of workers in the U.S. across an extensive range of occupations, which is another distinct strength of this study.

\section{Conclusions}

In conclusion, preliminary evidence of associations between stressful work in terms of effort-reward imbalance and drug misuse, in particular opioid misuse, was observed, calling for further empirical support by prospective observational studies. Ideally, these studies apply the model's original measurement tool and include objective data on drug misuse. In addition, specific vulnerability factors should be added to improve the accuracy of predictions. Once prospective findings corroborate the preliminary observation, worksite prevention approaches need to be developed to reduce future risks of drug misuse. Finally, given the scope of this problem, national policy measures of prevention and protection need to be adjusted to this new evidence.

Author Contributions: Conceptualization, J.L. and J.S.; methodology, J.L. and L.C.; data management, T.A.M.; data analysis, J.L. and T.A.M.; writing-original draft preparation, J.L., T.A.M. and J.S.; writing - review and editing, L.C., M.S. and C.L.; supervision, J.L. and J.S.; project administration, J.L.; funding acquisition, J.L. All authors have read and agreed to the published version of the manuscript.

Funding: This project was sponsored by a grant provided by the Council on Research of the Academic Senate of the Los Angeles Division of the University of California (Grant No.: J. Li FRG 20-21). Matthews and Li were also supported by a Start-Up Grant from the University of California, Los Angeles to $\mathrm{Li}$ as a new faculty member.

Institutional Review Board Statement: The study was conducted according to the guidelines of the Declaration of Helsinki, and reviewed and approved for exemption by the University of California, Los Angeles Institutional Review Board (IRB\#20-001043).

Informed Consent Statement: Informed consent was obtained from all subjects involved in the study.

Data Availability Statement: The raw data of the MIDUS study are publicly available from: https:/ / www.icpsr.umich.edu/web/pages/NACDA/midus.html (accessed on 6 November 2021). The statistical SAS syntax supporting the conclusions of this article will be made available by the authors, without undue reservation. Requests to access the statistical SAS syntax should be directed to Jian Li, jianli2019@ucla.edu.

Acknowledgments: The authors are grateful to the MIDUS research team for open access to the MIDUS study datasets. Publicly available data from the MIDUS study was used for this research. Since 1995 the MIDUS study has been funded by the following: John D. and Catherine T. MacArthur Foundation Research Network; National Institute on Aging (P01-AG020166); National Institute on Aging (U19-AG051426).

Conflicts of Interest: The authors declare no conflict of interest. The funders had no role in the design of the study, in the collection, analyses, or interpretation of data, in the writing of the manuscript, or in the decision to publish the results. 


\section{Appendix A}

Table A1. Proxy measures of effort-reward imbalance (ERI) at work.

\section{Effort}

(1) How often do you have to work very intensively-that is, you are very busy trying to get things done?

(2) How often do different people or groups at work demand things from you that you think are hard to combine?

(3) How often do you have too many demands made on you?

(4) How often do you have enough time to get everything done?

(5) How often do you have a lot of interruption?

(6) How often does your job require a lot of physical effort?

(7) How often does your job require you to lift loads weighing 50 pounds or greater?

(8) How often does your job require you to crouch, stoop, or kneel?

(9) How often does your job require you to stand for long periods of time?

(10) How often does your job require you to use stairs or inclines?

- $\quad$ Mental effort: items 1, 2, 3, 4, 5; Physical effort: items 6, 7, 8, 9, 10

- $\quad$ Response: All of the time/Most of the time/Some of the time/Rarely or Never

Reward

(1) To what extent do you feel cheated about the chances you have had to work at good jobs?

(2) To what extent do you feel a good deal of pride, when you think about the work you do on your job?

(3) To what extent do you feel that others respect the work you do on your job?

(4) To what extent do you feel that most people have more rewarding jobs than you do?

(5) To what extent do you feel that you've had opportunities that are as good as most people's, when it comes to your work life?

(6) To what extent do you feel that it makes you discouraged that other people have much better jobs that you do.

(7) If you wanted to stay in your present job, what are the chances that you could keep it for the next two years?

- Job promotion: items 1, 4, 5, 6; Esteem: items 2, 3; Job security: item 7

- $\quad$ Response: A lot/Some/A little/Not at all

\section{References}

1. Hawkins, D.; Punnett, L.; Davis, L.; Kriebel, D. The contribution of occupation-specific factors to the deaths of despair, Massachusetts, 2005-2015. Ann. Work Expo. Health 2021, 65, 819-832. [CrossRef] [PubMed]

2. Venkataramani, A.S.; Bair, E.F.; O'Brien, R.L.; Tsai, A.C. Association between automotive assembly plant closures and opioid overdose mortality in the United States: A difference-in-differences analysis. JAMA Intern. Med. 2020, 180, 254-262. [CrossRef] [PubMed]

3. Shaw, W.S.; Roelofs, C.; Punnett, L. Work environment factors and prevention of opioid-related deaths. Am. J. Public Health 2020, 110, 1235-1241. [CrossRef] [PubMed]

4. Choi, B. Opioid use disorder, job strain, and high physical job demands in US workers. Int. Arch. Occup. Environ. Health 2020, 93, 577-588. [CrossRef]

5. Kowalski-McGraw, M.; Green-McKenzie, J.; Pandalai, S.P.; Schulte, P.A. Characterizing the interrelationships of prescription opioid and benzodiazepine drugs with worker health and workplace hazards. J. Occup. Environ. Med. 2017, 59, 1114-1126. [CrossRef]

6. Howard, J.; Osborne, J. Cannabis and work: Need for more research. Am. J. Ind. Med. 2020, 63, 963-972. [CrossRef]

7. Phillips, J.A.; Holland, M.G.; Baldwin, D.D.; Meuleveld, L.G.; Mueller, K.L.; Perkison, B.; Upfal, M.; Dreger, M. Marijuana in the workplace: Guidance for occupational health professionals and employers: Joint guidance statement of the American Association of Occupational Health Nurses and the American College of Occupational and Environmental Medicine. J. Occup. Environ. Med. 2015, 57, 459-475. [CrossRef]

8. Hazle, M.C.; Hill, K.P.; Westreich, L.M. Workplace cannabis policies: A moving target. Cannabis Cannabinoid Res. 2020. [CrossRef]

9. Airagnes, G.; Lemogne, C.; Kab, S.; Hoertel, N.; Goldberg, M.; Wahrendorf, M.; Siegrist, J.; Roquelaure, Y.; Limosin, F.; Zins, M. Effort-reward imbalance and long-term benzodiazepine use: Longitudinal findings from the CONSTANCES cohort. J. Epidemiol. Community Health 2019, 73, 993-1001. [CrossRef]

10. Giurgiu, D.I.; Jeoffrion, C.; Grasset, B.; Dessomme, B.K.; Moret, L.; Roquelaure, Y.; Caubet, A.; Verger, C.; Laraqui Cel, H.; Lombrail, P.; et al. Psychosocial and occupational risk perception among health care workers: A Moroccan multicenter study. BMC Res. Notes 2015, 8, 408. [CrossRef]

11. Cooper, R.; Bixler, E.A. Comprehensive workplace policies and practices regarding employee opioid use. New Solut. 2021, 31, 219-228. [CrossRef]

12. Theorell, T. (Ed.) Handbook of Socioeconomic Determinants of Occupational Health; Springer Nature: Cham, Switzerland, 2020.

13. Jahoda, M. Reflections on Marienthal and after. J. Occup. Organ. Psych. 1992, 65, 355-358. [CrossRef] 
14. Karasek, R. Job demands, job decision latitude, and mental strain: Implications for job redesign. Adm. Sci. Q. 1979, 24, 285-308. [CrossRef]

15. Siegrist, J. Adverse health effects of high effort-low reward conditions at work. J. Occup. Health Psychol. 1996, 1, 27-43. [CrossRef]

16. Henry, J.P.; Stephens, P.M. Stress, Health, and the Social Environment: A Sociobiologic Approach to Medicine; Springer: New York, NY, USA, 1977.

17. McEwen, B.M. Physiology and neurobiology of stress and adaptation: Central role of the brain. Physiol. Rev. 2007, 87, 873-904. [CrossRef]

18. Karasek, R.; Theorell, T. Healthy Work. Stress, Productivity, and the Reconstruction of Working Life; Basic Books: New York, NY, USA, 1990.

19. Siegrist, J.; Li, J. Handbook of Socioeconomic Determinants of Occupational Health; Theorell, T., Ed.; Springer Nature: Cham, Switzerland, 2020; Volume 1, Chapter 19; pp. 355-382.

20. Evanoff, B.A.; Rohlman, D.S.; Strickland, J.R.; Dale, A.M. Influence of work organization and work environment on missed work, productivity, and use of pain medications among construction apprentices. Am. J. Ind. Med. 2020, 63, 269-276. [CrossRef]

21. Airagnes, G.; Lemogne, C.; Goldberg, M.; Hoertel, N.; Roquelaure, Y.; Limosin, F.; Zins, M. Job exposure to the public in relation with alcohol, tobacco and cannabis use: Findings from the CONSTANCES cohort study. PLoS ONE 2018, 13, e0196330. [CrossRef]

22. Milner, A.; Scovelle, A.J.; King, T.L.; Madsen, I. Exposure to work stress and use of psychotropic medications: A systematic review and meta-analysis. J. Epidemiol. Community Health 2019, 73, 569-576. [CrossRef]

23. Tan, E.C.; Pan, K.Y.; Hanson, L.L.; Fastbom, J.; Westerlund, H.; Wang, H.X. Psychosocial job strain and polypharmacy: A national cohort study. Scand. J. Work Environ. Health 2020, 46, 589-598. [CrossRef]

24. Lassalle, M.; Chastang, J.F.; Niedhammer, I. Working conditions and psychotropic drug use: Cross-sectional and prospective results from the French national SIP study. J. Psychiatr. Res. 2015, 63, 50-57. [CrossRef]

25. Lavigne, É.; Bourbonnais, R. Psychosocial work environment, interpersonal violence at work and psychotropic drug use among correctional officers. Int. J. Law Psychiatry 2010, 33, 122-129. [CrossRef]

26. Jones, J.D.; Mogali, S.; Comer, S.D. Polydrug abuse: A review of opioid and benzodiazepine combination use. Drug Alcohol Depend. 2012, 125, 8-18. [CrossRef]

27. Karjalainen, K.; Kuussaari, K.; Kataja, K.; Tigerstedt, C.; Hakkarainen, P. Measuring concurrent polydrug use in general populations: A critical assessment. Eur. Addict. Res. 2017, 23, 163-169. [CrossRef]

28. Muntaner, C.; Anthony, J.C.; Crum, R.M.; Eaton, W.W. Psychosocial dimensions of work and the risk of drug dependence among adults. Am. J. Epidemiol. 1995, 142, 183-190. [CrossRef]

29. Reed, P.L.; Storr, L.L.; Anthony, J.C. Drug dependence enviromics: Job strain in the work environment and risk of becoming drug-dependent. Am. J. Epidemiol. 2006, 163, 404-411. [CrossRef]

30. Ryff, C.; Almeida, D.M.; Ayanian, J.; Carr, D.S.; Cleary, P.D.; Coe, C.; Davidson, R.J.; Krueger, R.F.; Lachman, M.E.; Marks, N.F.; et al. Midlife in the United States (MIDUS 2), 2004-2006; Inter-University Consortium for Political and Social Research: Ann Arbor, MI, USA, 15 September 2021. [CrossRef]

31. Siegrist, J.; Starke, D.; Chandola, T.; Godin, I.; Marmot, M.; Niedhammer, I.; Peter, R. The measurement of effort-reward imbalance at work: European comparisons. Soc. Sci. Med. 2004, 58, 1483-1499. [CrossRef]

32. Kessler, R.C.; Andrews, G.; Mroczek, D.; Ustun, B.; Wittchen, H.U. The World Health Organization composite international diagnostic interview short-form (CIDI-SF). Int. J. Methods Psychiatr. Res. 1998, 7, 171-185. [CrossRef]

33. Kessler, R.C.; McGonagle, K.A.; Zhao, S.; Nelson, C.B.; Hughes, M.; Eshleman, S.; Wittchen, H.U.; Kendler, K.S. Lifetime and 12-month prevalence of DSM-III-R psychiatric disorders in the United States. Results from the National Comorbidity Survey. Arch. Gen. Psychiatry 1994, 51, 8-19. [CrossRef] [PubMed]

34. Glei, D.A.; Stokes, A.; Weinstein, M. Changes in mental health, pain, and drug misuse since the mid-1990s: Is there a link? Soc. Sci. Med. 2020, 246, 112789. [CrossRef]

35. U.S. Department of Agriculture; U.S. Department of Health and Human Services. Dietary Guidelines for Americans, $2020-2025$. 2020. Available online: https://www.dietaryguidelines.gov/sites/default/files/2020-12/Dietary_Guidelines_for_Americans_ 2020-2025.pdf (accessed on 10 December 2021).

36. Hendy, H.M.; Black, P.; Can, S.H.; Fleischut, A.; Aksen, D. Opioid abuse as maladaptive coping to life stressors in U.S. adults. J. Drug Issues 2018, 48, 560-571. [CrossRef]

37. Head, J.; Stansfeld, S.A.; Siegrist, J. Psychosocial work environment and alcohol dependence. Occup. Environ. Med. 2004, 61, 219-224. [CrossRef]

38. Schultz, W. Behavioral theories and the neurophysiology of reward. Annu. Rev. Psychol. 2006, 57, 87-115. [CrossRef]

39. Eisenberger, N.I. The neural bass of social pain: Evidence for shared representation with physical pain. Psychosom. Med. 2012, 74, 126-135. [CrossRef]

40. Blum, K.; Cull, J.G.; Braverman, E.R.; Comings, D.E. Reward deficiency syndrome. Am. Sci. 1996, 84, $132-145$.

41. Montano, D.; Li, J.; Siegrist, J. Work Stress and Health in a Globalized Economy: The Model of Effort-Reward Imbalance; Siegrist, J., Wahrendorf, M., Eds.; Springer: Cham, Switzerland, 2016; Volume 1, Chapter 2; pp. 21-42.

42. Tsutsumi, A.; Kayaba, K.; Nagami, M.; Miki, A.; Kawano, Y.; Ohya, Y.; Odagiri, Y.; Shimomitsu, T. The effort-reward imbalance model: Experience in Japanese working population. J. Occup. Health 2002, 44, 398-407. [CrossRef] 
43. Li, J.; Yang, W.; Cheng, Y.; Siegrist, J.; Cho, S.-I. Effort-reward imbalance at work and job dissatisfaction in Chinese healthcare workers: A validation study. Int. Arch. Occ. Environ. Health 2005, 78, 198-204. [CrossRef]

44. Juárez-Garcia, A.; Vera-Calzaretta, A.; Blanco-Gomez, G.; Gomez-Ortiz, V.; Hernandez-Mendoza, E.; Jacinto-Ubillus, J.; Choi, B. Validity of the effort/reward imbalance questionnaire in health professionals from six Latin-American countries. Am. J. Ind. Med. 2015, 58, 636-649. [CrossRef]

45. Gillen, M.; Yen, I.H.; Trupin, L.; Swig, L.; Rugulies, R.; Mullen, K.; Font, A.; Burian, D.; Ryan, G.; Janowitz, I.; et al. The association of socioeconomic status and psychosocial and physical workplace factors with musculoskeletal injury in hospital workers. Am. $J$. Ind. Med. 2007, 50, 245-260. [CrossRef]

46. Choi, B.; Ko, S.; Dobson, M.; Schnall, P.L.; Garcia-Rivas, J.; Israel, L.; Baker, D. Short-term test-retest reliability of the Job Content Questionnaire and Effort-Reward Imbalance Questionnaire items and scales among professional firefighters. Ergonomics 2014, 57, 897-911. [CrossRef]

47. Burgel, B.J.; Elshatarat, R.A. Psychosocial work factors and low back pain in taxi drivers. Am. J. Ind. Med. 2017, 60, 734-746. [CrossRef]

48. Feaster, M.; Arah, O.A.; Krause, N. Effort-reward imbalance and ambulatory blood pressure among female Las Vegas hotel room cleaners. Am. J. Ind. Med. 2019, 62, 523-534. [CrossRef]

49. Mutambudzi, M.; Siegrist, J.; Meyer, J.D.; Li, J. Association between effort-reward imbalance and self-reported diabetes mellitus in older U.S. workers. J. Psychosom. Res. 2018, 104, 61-64. [CrossRef]

50. Koch, P.; Schablon, A.; Latza, U.; Nienhaus, A. Musculoskeletal pain and effort-reward imbalance-A systematic review. BMC Public Health 2014, 14, 37. [CrossRef]

51. Rugulies, R.; Aust, B.; Madsen, I.E. Effort-reward imbalance at work and risk of depressive disorders. A systematic review and meta-analysis of prospective cohort studies. Scand. J. Work Environ. Health 2017, 43, 294-306. [CrossRef]

52. Friedman, S.R.; Krawczyk, N.; Perlman, D.C.; Mateu-Gelabert, P.; Ompad, D.C.; Hamilton, L.; Nikolopoulos, G.; Guarino, H.; Cerdá, M. The opioid/overdose crisis as a dialectics of pain, despair, and one-sided struggle. Front. Public Health 2020, $8,540423$. [CrossRef]

53. Hill, K.P. Medical marijuana for treatment of chronic pain and other medical and psychiatric problems: A clinical review. JAMA 2015, 313, 2474-2483. [CrossRef]

54. de Jonge, J.; van der Linden, S.; Schaufeli, W.; Peter, R.; Siegrist, J. Factorial invariance and stability of the Effort-Reward Imbalance Scales: A longitudinal analysis of two samples with different time lags. Int. J. Behav. Med. 2008, 15, 62-72. [CrossRef] 